Original article

\title{
Genetic pattern of cystic fibrosis patients in Azeri Turkish population
}

\author{
Morteza Jabarpoor-Bonyadi, Mandana Rafeey, Amir Vahedi, Leila Vahedi
}

Tabriz University of Medical Sciences, Tabriz, Iran.

Received 07 August 2016, Revised 19 September 2016, Accepted 13 October 2016

(C) 2016, Jabarpoor-Bonyadi M., Rafeey M., Vahedi A., Vahedi L.

(C) 2016, Russian Open Medical Journal

Abstract: Objective - This study was designed to analyze the genetic pattern of cystic fibrosis and effects on age, sex and mortality in the Azeri Turkish population in Iran.

Material and Methods - This study was a descriptive study that was conducted for cystic fibrosis patients in Azeri Turkish population in Iran from 2001 to 2014. Of 331 patients, the spectrum of cystic fibrosis transmembrane conductance regulator (CFTR) mutations in 263 patients was reviewed. Demographic and genetic data of patients were summarized by descriptive analysis as frequency, percentage, mean and median.

Results - The frequency consanguineous marriages was $196(59.2 \%)$ positive and $135(40.8 \%)$ negative with a significant difference $(\mathrm{P}=0.001)$. We identified 32 known mutations and 74 kinds of genotypes. The most common mutation and genotype were $\Delta \mathrm{F} 508138$ (26.2\%) and $\Delta \mathrm{F} 508 / \Delta \mathrm{F} 50841(15.5 \%)$, respectively. The most mortality rate had observed in $\Delta \mathrm{F} 508$ genotypes.

Conclusion - These findings indicate high frequency of consanguinity marriage in this area. A low frequency of the $\Delta \mathrm{F} 508$ mutation and detection 32 mutations reflect a heterogeneous spectrum of the mutations in this ethnic group. Further examinations are necessary on CFTR gene and affect these items on on age, sex and mortality.

Keywords: cystic fibrosis, genetic mutation, genotype, mortality

Cite as Jabarpoor-Bonyadi M, Rafeey M, Vahedi A, Vahedi L. Genetic pattern of cystic fibrosis patients in Azeri Turkish population. Russian Open Medical Journal 2017; 6: e0101.

Correspondence to Leila Vahedi. Tel.: +9141042900. Fax: +4133373741. E-mail: vahedi.149@gmail.com

\section{Introduction}

Cystic fibrosis (CF; OMIM 219700) is the most common lethal autosomal recessive disorder that involving some organs as the bronco pulmonary, gastrointestinal reproductive systems, and sweat glands [1-3]. Mutations on the cystic fibrosis transmembrane conductance regulator (CFTR) gene on chromosome $7 q 31.2$ result in this disease [4]. The incidence of $\mathrm{CF}$ in Middle East is unidentified, but it is probable to be 1 in 7,00010,000 compared with 2,000-3,000 live births in Europe [5-6].

More than 1,500 mutations and 300 polymorphisms have been reported for CF with the high prevalence of F508 mutation that $3 \mathrm{bp}$ deletion in exon 10, leading to the loss of the amino acid phenylalanine at position 508 [7-9].

The frequency of this mutationvaries in different regions and Ethnicities [10-12], with the highest rate in Denmark (90\%) and lowest in Tanzania (17.9\%), when the frequency of this mutation reduces from northwestern Europe to South East Europe and West Asia. It is estimated that the frequency of this mutation was 13$44 \%$ in the countries of Western Europe and Asia [13-15]. G542X, N1303K, G551D and W1282X mutations form almost 1\% of all mutations of CF among whites [16-17].

The retrospective researches, despite some disadvantages, have an essential role in depicting the disease and assessment impacts [18-19]. Sufficient knowledge of genetic pattern in a specific ethnic gives beneficial information about a specific disease. According to this information, the programmers of screening, phenotype-genotype correlation evaluation, and prenatal diagnosis would be designed for this disease.

This study reviewed genetic pattern in CF patients and effects on age, sex and mortality in the Azeri Turkish population in Iran.

\section{Material and Methods}

This was a cross sectional study performed on on 331 patients admitted to the Children's Educational and Treatment Hospital of the Tabriz University of Medical Sciences (Tabriz, Iran) and Medical Genetic Laboratory (Tabriz, Iran) from March 2001 to February 2015. This study was done on Azeri Turks who are one the largest ethnic groups in Iran [4], and Tabriz is the second biggest city in Iran. Data was acquired from medical records by censes method.

The diagnosis of CF was based on the typical clinical presentations and the identification of mutations in CFTR gene known to cause CF or abnormal sweat chloride values (>60 mEq/L) according to the method of Gibson and Cooke [20].

Deoxyribonucleic acid (DNA) of patients after extracting from peripheral blood leukocytes according to standard protocols [21] were amplified by polymerase chain reaction (PCR) and products were screened using single-stranded conformational polymorphism / heteroduplex analysis (SSCP/HD) or Sanger sequencing. 
Table 1. The most common of Genotype distribution in patients with cystic fibrosis

\begin{tabular}{lc}
\hline \multicolumn{1}{c}{ Genotype } & Frequency, no. (\%) \\
\hline F508/ F508 & $41(15.5)$ \\
F508/unidentified $\Delta$ & $33(12.5)$ \\
1540G-A/unidentified & $33(12.5)$ \\
1540G-A/ 1540G-A & $10(3.8)$ \\
F508/1540G-A $\Delta$ & $9(3.4)$ \\
M470V/unidentified & $9(3.4)$ \\
M470V/M470V & $8(3.0)$ \\
1677delTA/ unidentified & $7(2.7)$ \\
1525-61A-G/1540G-A & $7(2.7)$ \\
2183AA-G/unidentified & $7(2.7)$ \\
1677delTA/1677delTA & $7(2.7)$ \\
2789G-A/2789G-A & $5(1.9)$ \\
1525-61A-G/M470V & $5(1.9)$ \\
A120T/unidentified & $4(1.5)$ \\
G542X/unidentified & $4(1.5)$ \\
2183AA-G/2183AA-G & $3(1.1)$ \\
3849+5G-A/unidentified & $3(1.1)$ \\
2043delG/2043delG & $3(1.1)$ \\
2789G-A/2789G-A & $2(0.8)$ \\
K1302X/K1302X & $2(0.8)$ \\
406-6T-C/unidentified & $2(0.8)$ \\
2043delG/unidentified & $2(0.8)$ \\
G542X/ G542X & $2(0.8)$ \\
F508/2789+5G-A $\Delta$ & $2(0.8)$ \\
2184insA/unidentified & $2(0.8)$ \\
2184insA/2184insA & $2(0.8)$ \\
S466X/unidentified & $2(0.8)$ \\
S466X/S466X & $2(0.8)$ \\
The rest genotypes had frequency under & \\
\hline &
\end{tabular}

The genetic results of patients were separately reviewed by two authors. Kappa agreement rate was higher than $85 \%$. Data was calculated by descriptive analyses including mean (M), standard deviation (SD), frequency, percentage, median (Me), maximum (Max), and minimum (Min) using SPSS 18. $\mathrm{P}<0.05$ was considered significant difference.

\section{Results}

\section{Demographic data}

A total of 331 patients, 191 patients (57.7\%) were males and 140 patients $(42.3 \%)$ - females that this difference was statistically significant $(P<0.001)$. There were $85(25.7 \%)$ dead patients and 246 $(74.3 \%)$ alive patients at the time of the study and median age was considered for alive patients that was 4.76 years $(0.42-43.41$ years). The variable of consanguineous marriages had been reviewed among patients that 196 (59.2\%) were positive for consanguineous marriages and 135 (40.8\%) negative with a significant difference $(P=0.001)$.

\section{Genetic results}

At genetic results, 263 patients of 331 were enrolled into our study during the 14-year period. Sixty eight records were included because of incomplete data. There were 526 alleles and 32 variants $(45.5 \%$ CF-causing, $31.5 \%$ polymorphisms, $15.5 \%$ missense, and $7.5 \%$ splicing). Of 526 mutant alleles, 16 variants (almost half) had a frequency of less than $1 \%$. The $\Delta \mathrm{F} 508$ with frequency 138 (26.3\%) was the most commonmutation that was followed by 1677delTA $23(4.3 \%)$ in our population. The distribution of CFTR mutations is shown in Table 2.

The genotype was survived among patients. There were 74 kinds of genotypes with the highest frequency of $\Delta \mathrm{F} 508 / \Delta \mathrm{F} 50841$ (15.5\%) genotype. More genotypes were heterozygote $(62.4 \%)$ in compassion with homozygote genotypes (37.6\%). The distribution of the most common CFTR genotypes is shown in Table 1.

\section{Assessment the effect of age, gender and mortality rate on genetic pattern}

At this part, DF508, 1677delT, G542X, 2183AA-G, 2043delG, 1540G-A, M470V, and 1525-61A-G mutations reviwed and the rest mutations were ignored because of less number. The results of effects age, gender and mortality rate on genetic pattern are shown in Table 3.

\section{Discussion}

$\mathrm{CF}$ is an autosomal recessive disease that numerous mutations in the CFTR gene have been reported as a primary cause. The aim of this study was to evaluate the molecular defects in CF alleles in the Azeri Turkish population in Iran.

When we evaluated the demographic results of this study, a significant difference observed between males and females. Core et al. had reported the male to female ratio approximately 1.2/1.0 with no significant difference in Boston and Toronto [22]. In addition, other studies as Jackson et al. [23] showed this gender gap in CF patients with no a difference significant. Therefore, this gender gap in our population may be related to cultural subjects [24], religious issues [25] or an intrinsic ethnic difference [23].

In this study, the mean age of was lower in comparison with other studies. For instance, in the study which Core et al. had conducted the mean ages were $15.2 \pm 8.3$ years and $15.9 \pm 9.6$ years in Toronto and Boston, respectively [22].

The rate of consanguinity marriage has been reported to $56 \%$ in Middle East with the highest rate in Saudi Arabia. Therefore genetic disease observed more commonly in these countries [2628 ]. In our population, the rate of consanguinity marriage was approximately to $41 \%$.

The Middle East has the highest CFTR heterogeneity, that analysis and diagnosis can be difficult [4].

Singh and colleagues carried out a review about genetic status CF in Asia in 2015 [29]. For Pakistani population with CF, over 340 mutant alleles, 4 mutation types with $17 \%$ for $\Delta \mathrm{F} 508$, for the Lebanese patients, among 84 mutant alleles, 13 mutation types with $36.3 \%$ for $\triangle \mathrm{F} 508$, and for Turkish patients, among 423 mutant alleles, 29 mutation types with $22.46 \%$ for $\Delta \mathrm{F} 508$ have been reported [29].

In one studyof Xavier Estivill et al., 272 CF patients from 29 European countries and 3 North African countries have been investigated that the most mutations associated with $\Delta \mathrm{F} 508$ (66.8\%), G542X (2.6\%), N1303K (1.6\%), G551D (1.5\%) and W1282X (1\%). The highest frequency of $\triangle \mathrm{F} 508$ mutation related to Denmark country with $87.2 \%$ and the lowest in Algeria with $26.3 \%$ [30].

In 2015, Shen et al. have conducted a study on 21 Chinese CFpatients. In this study, M470V polymorphism has been observed with a high rate [31]. 
Table 2. Mutations and the frequency of alleles in patients with cystic fibrosis

\begin{tabular}{|c|c|c|c|c|}
\hline cDNA Name & Protein Name & Legacy Name & Description & Alleles-Frequency, no. (\%) \\
\hline c.1521-1523delCTT & p.Phe508del & Delta $\Delta \mathrm{F} 508$ & Deletion 3 bp between 1652 and 1655 & $138(26.2)$ \\
\hline c. $1540 G>A$ & p.Glu514Lys & - & - & $90(17.1)$ \\
\hline c. $1408 \mathrm{~A}>\mathrm{G}$ & p.Met470Val & M470V & A or $\mathrm{G}$ at 1540 & $42(8.0)$ \\
\hline c.1545-546delTA & p.Tyr515X & 1677delTA & Deletion TA from 1677 & $23(4.3)$ \\
\hline c. $1393-61 A>G$ & - & $1525-61 \mathrm{~A} / \mathrm{G}$ & A or $\mathrm{G}$ at $61-1525$ & $22(4.2)$ \\
\hline c.2051-2052delAAinsG & p.Lys684SerfsX38 & $2183 A A>G(2184$ delA) & A or G at 2183, Deletion A at 2184 & $14(2.7)$ \\
\hline c. $2789 \mathrm{G}>\mathrm{A}$ & p.Gly930Glu & - & - & $11(2.1)$ \\
\hline c. $1624 G>T$ & p.Gly542X & G542X & $\mathrm{G}$ to $\mathrm{T}$ at 1756 & $10(1.9)$ \\
\hline c. $2657+5 G>A$ & - & $2789+5 G>A$ & $\mathrm{G}$ to $\mathrm{A}$ at $5+2789$ & $7(1.3)$ \\
\hline c. $1397 C>G$ & p.Ser466X & S466X(TAG) & C to $\mathrm{G}$ at 1529 & $7(1.3)$ \\
\hline c. $3905 A>G$ & p.Lys1302Arg & K1302R & A to $G$ at 4037 (AAA >AGA) & $7(1.3)$ \\
\hline c.1911delG & p.GIn637HisfsX26 & 2043delG & Deletion G at 2043 & $7(1.3)$ \\
\hline c.2052-2053insA & p.GIn685ThrfsX4 & 2184insA & Adding $\mathrm{A}$ after & $6(1.1)$ \\
\hline c.3469-65C>A & - & $3601-65 C / A$ & $C$ to $A$ at $65-3601$ & $6(1.1)$ \\
\hline c. $1000 C>T$ & p.Arg334Trp & R334W & C to $T$ at 1132 & $6(1.1)$ \\
\hline c. $358 \mathrm{G}>\mathrm{A}$ & p.Ala120Thr & A120T & $\mathrm{G}$ to $\mathrm{A}$ at 490 & $5(0.9)$ \\
\hline c. $274 G>A$ & Glu92Lys & E92k & - & $4(0.8)$ \\
\hline c. $3717+5 G>A$ & - & $3849+5 G>A$ & $\mathrm{G}$ to $\mathrm{A}$ at $5+3849$ & $3(0.6)$ \\
\hline c.3964-283T>C & - & 4096- 283T/C & T or $\mathrm{C}$ at $283-4069$ & $3(0.6)$ \\
\hline c. $1116+1 G>A$ & - & $1248+1 G>A$ & $\mathrm{G}$ to $\mathrm{A}$ at $1+1248$ & $2(0.4)$ \\
\hline c. $1584+1 G>A$ & - & $1716+1 G>A$ & $\mathrm{G}$ to $\mathrm{A}$ at $1+1716$ & $2(0.4)$ \\
\hline c. $1393-1 \mathrm{G}>\mathrm{A}$ & - & $1525-1 G>A$ & $\mathrm{G}$ to $\mathrm{A}$ at $1-1525$ & $2(0.4)$ \\
\hline $274-6 T>C$ & - & $406-6 \mathrm{~T}>\mathrm{C}$ & - & $2(0.4)$ \\
\hline c. $328 \mathrm{G}>\mathrm{C}$ & p.Asp $110 \mathrm{His}$ & D110H & $\mathrm{G}$ to $\mathrm{C}$ at 460 & $2(0.4)$ \\
\hline c. $1585-2 A>G$ & - & $1717-2 A>G$ & A to $\mathrm{G}$ at $2-1717$ & $2(0.4)$ \\
\hline c.3529A $>\mathrm{T}$ & p.Lys1177X & K1177X & A to $T$ at 3661 & $2(0.4)$ \\
\hline c.2998delA & p.lle1000LeufsX2 & 3130delA & Deletion A at 3130 & $1(0.2)$ \\
\hline c. $3472 C>T$ & p.Arg1158X & $\mathrm{R} 1158 \mathrm{X}$ & C to $T$ at 3604 & $1(0.2)$ \\
\hline c. $332 C>T$ & p.Pro111Leu & P111L & C to $\mathrm{T}$ at 464 & $1(0.2)$ \\
\hline c. $3154 \mathrm{~T}>\mathrm{G}$ & p.Phe1052Val & F1052V & T to $\mathrm{G}$ at 3286 & $1(0.2)$ \\
\hline c. $443 T>C$ & p.lle148Thr & I148T & $\mathrm{T}$ to $\mathrm{C}$ at 575 & $1(0.2)$ \\
\hline c. $254 \mathrm{G}>\mathrm{A}$ & p.Gly85Glu & G85E & $\mathrm{G}$ to $\mathrm{A}$ at 386 & $1(0.2)$ \\
\hline Unknown polymorphisms & - & - & - & $7(1.3)$ \\
\hline Unidentified & - & - & - & $88(16.7)$ \\
\hline Total & - & - & - & $526(100)$ \\
\hline
\end{tabular}

Table 3. The effects of age, gender and mortality rate on genetic pattern

\begin{tabular}{|c|c|c|c|c|c|c|c|}
\hline № & Mutations & Total, no. (\%) & Male, no. (\%) & Deceased pat., no. (\%) & Living pat., no. (\%) & Age at death & Age for living CF pat. \\
\hline 1 & DF508 & $91(43.3)$ & $39(42.9)$ & $15(16.5)$ & $76(83.5)$ & $3.0(0,30.1)$ & $6.8(1.4,16.0)$ \\
\hline 2 & 1677delT & $15(7.1)$ & $9(60)$ & 0 & $15(100)$ & - & $3.8(0,5.4)$ \\
\hline 3 & G542X & $8(3.8)$ & $5(62.5)$ & $2(25)$ & $6(75.0)$ & $2.5(0,30.2)$ & $6.9(0,25.1)$ \\
\hline 4 & 2183AA-G & $10(4.8)$ & $7(70)$ & 0 & $10(100)$ & - & $1.0(0,20.0)$ \\
\hline 5 & 2043delG & $5(2.4)$ & $2(40)$ & 0 & $5(100)$ & - & $0.4(0,30.0)$ \\
\hline 6 & 1540G-A & 46 (21.9) & $33(71.7)$ & $8(17.4)$ & $38(82.6)$ & $2.7(0,32.0)$ & $6.9(0,25.1)$ \\
\hline 7 & M470V & $18(8.6)$ & $13(72.2)$ & $1(5.6)$ & $17(94.4)$ & $0.4(0,30.0)$ & $1.1(0,23.5)$ \\
\hline \multirow[t]{2}{*}{8} & $1525-61 A-G$ & $17(8.1)$ & $6(35.3)$ & 0 & $17(100)$ & - & $3.6(0,11.5)$ \\
\hline & Total & 210 & 114 & 26 & 184 & - & - \\
\hline
\end{tabular}

pat., patients. Quantitative data are presented as Me (Min, Max).

When the genetic pattern was compared with others, the frequency of the $\Delta \mathrm{F} 508$ mutation was lower than Northern and Western European countries, although this mutation was the most common mutations in this population.

$\mathrm{CF}$ is a monogenic disease inherited as autosomal-recessive disorder [32]. The majority of CF patients was classified as classical $\mathrm{CF}$ and usually has two mutations on each allele. These mutations usually are disease-causing gene mutations. Therefore, the identification of CFTR genotype, an analysis of diagnostic testing is necessary [32-34].
Rodman et al. have been reportedthe distribution of CFTR genotypes between 1992 and 2004 at Colorado. In this study, $\Delta \mathrm{F} 508(20 \%)$ and $\Delta \mathrm{F} 508 / \Delta \mathrm{F} 508$ (36.3\%) were the common mutation and genotype, respectively [32].

In another study, Gökdemir et al. have been investigated on $200 \mathrm{CF}$ patients that the most common genotype was $\Delta \mathrm{F} 508 / \Delta \mathrm{F} 508$ or $\Delta \mathrm{F} 508 /$ other mutations. In heterozygote individuals, $\Delta \mathrm{F} 508$ has been observed with L571, 2789+5G>A, 2183AA-G, 1262insG, 1507del, and N1303K mutations [35].

Pandith et al. carried out a study on 150 CF patients who plays consanguinity an important role in the pathogenesis of this 
disease. So that consanguinity rate was $53.4 \%$ and more the kind of First Cousin [36].

Lucarelli et al have found valuable results in Italy. They have enrolled approximately 600 patients with various forms of CF. Generally, 125 different mutated alleles and 225 genotypes have been observed, that illustrates a high degree of heterogeneity in the spectrum of mutations and genotypes CFTR with predominancethe DF508 mutation. The consanguineous marriage is not mentioned that this is probably because of the low levels of this subject. Complex genotypes have been seen accompanied by DF508 mutation in most cases. However, because of progress on molecular diagnostic techniques, the frequency of unknown alleles was very low [37].

DF508, 1677delT, M470V, and 1525-61A-G mutations had been observed further in female patients, in cotrast G542X, 2183AA-G, 2043delG, and 1540G-A mutations in male patients. At 1677delT, 2183AA-G, 2043delG, and 1525-61A-G mutations had not been observed any mortality and more deaths related to DF508, and G542X mutations. $\triangle F 508$ and G542X mutations happen in exon 11 and 12 that encode NBD1 in CFTR Protein. These mutations, a variety of CF-Causing, were classified as class II and class I (severe form), respectively with sever clinical presentations [38].

In a study have performed by McKone et al. about effect of genotype on phenotype in cystic fibrosis from 1991 to 1999, there were 1547 deaths over the 9 years. In this study, classes IV and V had milder clinical manifestations and lower mortality rate than classes I and II. The most deaths associated with genotype for $\Delta \mathrm{F} 508$ [39].

In current study, the least mortality age had been obsorved in M470V mutation. Since, the number of undetected mutations was high quantity in our study, it is likely that have not been detected the mutations of severe forms concomitance M470V mutation.

In study McKone et al. association of CFTR genotype with mortality in CF-patients was investigated. Sweat chloride concentration impact on death age, howerver CFTR genotype had considered as independently factor on survival [40].

It is necessary that more studies carried out on correlation genotype with phenotype, mortality and survival, in the future.

\section{Conclusion}

We found that this disease was more common in younger males. Consanguineous marriage still continues in this area in spite of problems. A large variety of mutations was observed for CF with priority pathogenic variants, although was observed genetic polymorphism and splicing types. The $\Delta \mathrm{F} 508$ mutation and $\Delta \mathrm{F} 508 /$ $\Delta \mathrm{F} 508$ genotype had the most frequency in this region. We had several unknown variants among samples that it looks the extensive review of CFTR gene and the utilization of advanced molecular testings is nessasery. Genetic pattern effects on course of disease.

\section{Limitations and Strength Points}

There were some limitations in current study. This was a retrospective study and was performed in a specialist group. Data was limited to Children's Hospital of the University of Medical Sciences and Medical Genetic Laboratory in Tabriz. It may be that CF patients were diagnosed without recording or not referred to these centers. In addition, this search has been limited between 2001 and 2015.
The strength of this study was the proper sample size considering the low incidence of CF in this area. Data approved by two appraisal persons, was gathered from educational, therapeutic and referral centers over a long period of time.

\section{Ethical Issues}

We have not done any research procedures on human or animal. Ethical facets were considered while approving the proposal by the Ethics Committee of the Tabriz University of Medical Sciences ( $\mathrm{No}=5 / 4 / 1775)$ and information was kept secret even from the data analyzers.

Conflict of interest: none declared.

\section{Acknowledgments}

We would like to thank Liver and Gastrointestinal Disease Research Center, Children's Hospital of the Tabriz University of Medical Sciences (Tabriz, Iran).

\section{References}

1. Ernst MM, Johnson MC, Stark U. Developmental and psychosocial issues in cystic fibrosis. Child Adolesc Psychiatr Clin N Am 2010; 19: 263-283. https://dx.doi.org/10.1016/i.chc.2010.01.004.

2. Haworth C, Selby P, Horrocks A, Mawer E, Adams J, Webb A. A prospective study of change in bone mineral density over one year in adults with cystic fibrosis. Thorax 2002; 57: 719-723. https://dx.doi.org/10.1136/thorax.57.8.719.

3. Sordé R, Pahissa A, Rello J. Management of refractory Pseudomonas aeruginosa infection in cystic fibrosis. Infect Drug Resist 2011; 4: 31. https://dx.doi.org/10.2147/IDR.S16263.

4. Bonyadi M, Omrani O, Rafeey M, Bilan N. Spectrum of CFTR gene mutations in Iranian Azeri Turkish patients with cystic fibrosis. Genetic Testing and Molecular Biomarkers 2010; 15(1-2): 89-92. https://dx.doi.org/10.1089/gtmb.2010.0091.

5. Salvatore $D$, Buzzetti $R$, Baldo E, Forneris MP, Lucidi V, Manunza D, et al. An overview of international literature from cystic fibrosis registries. Part 3. Disease incidence, genotype/phenotype correlation, microbiology, pregnancy, clinical complications, lung transplantation, and miscellanea. J Cyst Fibros 2011; 10: 71-85. https://dx.doi.org/10.1016/i.jcf.2010.12.005.

6. Farrell P, Joffe S, Foley L, Canny G, Mayne P, Rosenberg M. Diagnosis of cystic fibrosis in the Republic of Ireland: epidemiology and costs. Ir Med J 2007; 100(8): 557-560. https://www.ncbi.nlm.nih.gov/pubmed/17955689.

7. Dooki MRE, Tabaripour R, Rahimi R, Akhavan-Niaki H. Mutation and new polymorphismsinsight in introns 11 to 14 a of CFTR gene of northern Iranian cystic fibrosis patients. Gene 2015; 564(2): 193-196. https://dx.doi.org/10.1016/j.gene.2015.03.056.

8. Sosnay PR, Siklosi KR, Van Goor F, Kaniecki K, Yu H, Sharma N, et al. Defining the disease liability of variants in the cystic fibrosis transmembrane conductance regulator gene. Nature Genetics 2013; 45(10): 1160-1167. https://dx.doi.org/10.1038/ng.2745.

9. Yvert T, Santiago C, Santana-Sosa E, Verde Z, Gómez-Gallego F, LopezMojares L, et al. Physical-capacity-related genetic polymorphisms in children with cystic fibrosis. Pediatric Exercise Science 2015; 27(1): 102-112. https://dx.doi.org/10.1123/pes.2014-0050.

10. Schippa S, lebba V, Santangelo F, Gagliardi A, Biase R V, Stamato A, et al. Cystic fibrosis transmembrane conductance regulator (CFTR) allelic variants relate to shifts in faecal microbiota of cystic fibrosis patients. PLoS One 2013; 8(4): e61176. https://dx.doi.org/10.1371/journal.pone.0061176. 
11. Alibakhshi A, Zamani M. Mutation analysis of CFTR gene in 70 Iranian cystic fibrosis patients. Iran J Allergy Asthma Immunol 2006; 5(1): 3-8. https://dx.doi.org/05.01/ijaai.38.

12. Castellani C, Cuppens $H$, Macek M, Cassiman JJ, Kerem E, Durie P, et al. Consensus on the use and interpretation of cystic fibrosis mutation analysis in clinical practice. J Cyst Fibros 2008; 7(3): 179-196. https://dx.doi.org/10.1016/i.jcf.2008.03.009.

13. Liu J, Lissens W, Silber SJ, Devroey P, Liebaers I, Van Steirteghem A. Birth after preimplantation diagnosis of the cystic fibrosis $\Delta F 508$ mutation by polymerase chain reaction in human embryos resulting from intracytoplasmic sperm injection with epididymal sperm. JAMA 1994; 272(23): 1858-1860. https://dx.doi.org/10.1001/jama.1994.03520230068040.

14. Bobadilla JL, Macek M, Fine JP, Farrell PM. Cystic fibrosis: a worldwide analysis of CFTR mutations - correlation with incidence data and application to screening. Human Mutation 2002; 19(6): 575-606. https://dx.doi.org/10.1002/humu.10041.

15. Kabra S, Kabra M, Lodha R, Shastri S, Ghosh M, Pandey R, et al. Clinical profile and frequency of delta 508 mutation in Indian children with cystic fibrosis. Indian Pediatrics 2003; 40(7): 612-619. https://dx.doi.org/10.1111/resp.12656.

16. Johansen HK, Nir M, KochC, Schwartz M, Hớby N. Severity of cystic fibrosis in patients homozygous and heterozygous for $\Delta \mathrm{F} 508$ mutation. Lancet 1991; 337(8742): 631-634. https://dx.doi.org/10.1016/01406736(91)92449-C.

17. Van Goor F, Yu H, Burton B, Hoffman BJ. Effect of ivacaftor on CFTR forms with missense mutations associated with defects in protein processing or function. J Cyst Fibros 2010; 13(1): 29-36. https://dx.doi.org/10.1016/j.jcf.2013.06.008.

18. Mahadeva R, Webb K, Westerbeek RC, Carroll NR, Dodd ME, Bilton D, et al. Clinical outcome in relation to care in cen-tres specialising in cystic fibrosis: cross sectional study. BMJ 1998; 316: 1771-1775. https://dx.doi.org/10.1136/bmj.316.7147.1771.

19. Schechter MS, Shelton BJ, Margolis PA, Fitzsimmons SC. The association of socioeconomic status with outcomes in cystic fibrosis patients in the United States. Am J Respir Crit Care Med 2001; 163(6): 1331-1337. https://dx.doi.org/10.1164/ajrccm.163.6.9912100.

20. De Boeck K, Bulteel V, Tiddens H, Wagner T, Fajac I, Conway S, et al. Guideline on the design and conduct of cystic fibrosis clini-cal trials: The european cystic fibrosis society-clinical trials net-work (ECFSCTN). J Cyst Fibros 2011; 10: S67-S74. https://dx.doi.org/10.1016/S1569-1993(11)60010-6.

21. Miller SA, Dykes DD, Polesky HF. A simple salting out procedure for extracting DNA from human nucleated cells. Nucleic Acids Res 1988; 16: 1215. https://www.ncbi.nlm.nih.gov/pubmed/3344216.

22. Corey $M$, McLaughlin F, Williams $M$, Levison $H$. A comparison of survival, growth, and pulmonary function in patients with cystic fibrosis in Boston and Toronto. Journal of Clinical Epidemiology 1988; 41(6): 5835-5891. https://dx.doi.org/10.1016/0895-4356(88)90063-7.

23. Jackson A, Foley L, Daly L, Fitzpatrick $P$, Harrington $M$, Zhou $S$, et al. Delayed cystic fibrosis presentation in children in the absence of newborn screening. Irish Medical Journal 1988; 103(4): 113. https://www.ncbi.nlm.nih.gov/pubmed/20486315.

24. Driscoll KA, Montag-Leifling K, Acton JD, Modi AC. Relations between depressive and anxious symptoms and quality of life in caregivers of children with cystic fibrosis. Pediatric Pulmonology 2009; 44(8): 784792. https://dx.doi.org/10.1002/ppul.21057.

25. Bradley GM, Blackman SM, Watson CP, Doshi VK, Cutting GR. Genetic modifiers of nutritional status in cystic fibrosis. Am J Clin Nutr 2012; 96(6): 1299-1308. https://dx.doi.org/10.3945/ajcn.116.139444.

26. EL Mouzan MI, Al Salloum AA, Al Herbish AS, Qurachi MM, Al Omar AA. Consanguinity and major genetic disorders in Saudi children: a community-based cross-sectional study. Ann Saudi Med 2008; 28(3): 169-173. https://www.ncbi.nlm.nih.gov/pubmed/18500181.
27. Vahedi L, Jabarpoor-Bonyadi M, Ghojazadeh M, Hazrati H, Rafeey M. Association between outcomes and demographic factors in an Azeri Turkish population with cystic fibrosis: a cross-sectional study in Iran from 2001 through 2014. Iran Red Crescent Med J 2016; 18(4): e29615. https://dx.doi.org/10.5812\%2Fircmj.29615.

28. Hamamy $\mathrm{H}$. Consanguineous marriages: preconception consultation in primary health care settings. J Community Genet 2012; 3(3): 185-192. https://dx.doi.org/10.1007/s12687-011-0072-y.

29. Singh M, Rebordosa C, Bernholz J, Sharma N. Epidemiology and genetics of cystic fibrosis in Asia: In preparation for the next-generation treatments. Respirology 2015; 20(8): 1172-1181. https://dx.doi.org/10.1111/resp.12656.

30. Estivill X, Bancells C, Ramos C. Geographic distribution and regional origin of 272 cystic fibrosis mutations in European populations. Human Mutation 1997; 10(2): 135. https://dx.doi.org/10.1002/(SICI)10981004(1997)10:2\%3C135::AID-HUMU6\%3E3.0.CO;2-J.

31. Shen Y, Liu J, Zhong L, Mogayzel PJ, Zeitlin PL, Sosnay PR, et al. Clinical phenotypes and genotypic spectrum of cystic fibrosis in Chinese children. J Pediatr 2016; 171: 269-276. https://dx.doi.org/10.1016/i.jpeds.2015.12.025.

32. Rodman DM, Polis JM, Heltshe SL, Sontag MK, Chacon C, Rodman RV et al. Late diagnosis defines a unique population of long-term survivors of cystic fibrosis. Am J Respir Crit Care Med 2005; 171: 621-626. https://dx.doi.org/10.1164/rccm.200403-4040C.

33. Cohen-Cymberknoh M, Yaakov $Y$, Shoseyov D, Shteyer E, Schachar $E$, RivlinJ et al. Evaluation of the intestinal current measurement method as a diagnostic test for cystic fibrosis. Pediatric Pulmonology 2013; 48 : 229-235. https://dx.doi.org/10.1002/ppul.22586.

34. Vahedi L, Jabarpoor-Bonyadi M, Ghojazadeh M, Vahedi A, Rafeey M. Gender differences in clinical presentations of cystic fibrosis patients in Azeri Turkish population. Tuberc Respir Dis 2016; 79: 1-7. https://dx.doi.org/10.4046/trd.2016.79.4.1.

35. Gokdemir Y, Erdem E, Akpinar IN, Ersu R, Karadag B, Karakoc F. Other risk factors associated with mortality in moderate and severe cystic fibrosis patients. Turk Pediatri Arsivi-Turkish Archives of Pediatrics 2012; 47(4): 267-271. https://dx.doi.org/10.1016/j.jcf.2007.07.008

36. Pandith AA, Sheikh SA, Faheem S, Zargar MH, Malla TM, Shah ZA, et al. Identification of unique pattern of CFTR gene mutations in cystic fibrosis in an ethnic Kashmiri Population (North India). Journal of Genetic Syndromes \& Gene Therapy 2015; 6(2): 2157-7412. https://dx.doi.org/10.4172/2157-7412.1000260.

37. Lucarelli M, Bruno SM, Pierandrei S, Ferraguti G, Stamato A, Narzi F, et al. A genotypic-oriented view of CFTR genetics highlights specific mutational patterns underlying clinical. Mol Med 2015; 21(1): 257-275. https://dx.doi.org/10.2119/molmed.2014.00229.

38. Cystic Fibrosis Mutation Database. www.genet.sickkids.on.ca.

39. McKone EF, Emerson SS, Edwards KL, Aitken ML. Effect of genotype on phenotype and mortality in cystic fibrosis: a retrospective cohort study. Lancet 2003; 361(9370): 1671-1676. https://dx.doi.org/10.1016/S0140-6736(03)13368-5.

40. McKone EF, Velentgas P, Swenson AJ, Goss CH. Association of sweat chloride concentration at time of diagnosis and CFTR genotype with mortality and cystic fibrosis phenotype. Journal of Cystic Fibrosis 2015; 14(5): 580-586. https://dx.doi.org/10.1016/j.jcf.2015.01.005.

\section{Authors:}

Morteza Jabarpoor-Bonyadi - Associate Professor of Medical Genetic, Liver and Gastrointestinal Disease Research Center, Tabriz University of Medical Sciences, Tabriz, Iran.

Mandana Rafeey - Professor of Pediatric Gastroenterology, Liver and Gastrointestinal Disease Research Center, Children's Hospital, Tabriz University of Medical Sciences, Tabriz, Iran.

Amir Vahedi - Associate Professor of Pathology (Molecular Genetic), Department of Pathology, Liver and Gastrointestinal Disease Research Center, Tabriz University of Medical Sciences, Tabriz, Iran. 
Leila Vahedi - MD, PhD, Liver and Gastrointestinal Disease Research

Center, Tabriz University of Medical Sciences, Tabriz, Iran. http://orcid.org/0000-0003-0661-5885. 